\title{
Post traumatic knee arthritis: Navigated total knee replacement without hardware removal
}

\author{
Alfonso Manzotti ${ }^{a, *}$, Chris Pullen ${ }^{b}$, Pietro Cerveri ${ }^{c}$, Cesare Chemello ${ }^{d}$, Norberto Confalonieri ${ }^{a}$ \\ a Ist Orthopedic Department, C.T.O. Hospital, Via Bignami 1, 20100 Milan, Italy \\ b Orthopaedic Department, Royal Melbourne Hospital, Parkville, Victoria, Australia \\ c Bioengineering Department, Politecnico di Milano, 20100 Milan, Italy \\ d Clinica Ortopedica, Azienda Ospedaliera di Padova, Via Giustiniani 2, 35123 Padova, Italy
}

Received 6 February 2012

Received in revised form 16 June 2012

Accepted 18 June 2012

\section{Introduction}

The incidence of knee arthritis after femoral fracture is considerably less than following tibial plateau fracture. Distal femoral fracture more frequently leads to knee arthritis and this may be related to residual malalignment or direct intra-articular injury. Therefore, it is not infrequent for orthopedic surgeons to deal with patients following femoral fractures who have developed end stage arthritis requiring total knee replacement (TKR) [1-3]. In this situation the presence of retained hardware often combined with femoral sclerosis can make the use of intramedullary guides difficult during the replacement procedure [4]. Staged surgical procedures to remove the hardware combined with femoral osteotomy to correct posttraumatic deformity may be required in these cases before TKR. However, multiple surgical procedures prior to knee replacement have been linked to an increased risk of

\footnotetext{
* Corresponding author at: Via S Pertini 21, 20040 Cambiago (Milan), Italy. Fax: +39 257993905.

E-mail address: alf.manzotti@libero.it (A. Manzotti).
}

arthrofibrosis and infection [3]. Simultaneous arthroplasty and removal of hardware may require either two incisions or the use of a skin flap for adequate exposure both increasing the risks of soft tissue necrosis and septic contamination. In addition, the screw holes left after hardware removal are potential stress risers which may limit post-operative weight bearing or require additional support such as stems, intra-medullary rods, and strut allografts [5,6]. In 1998 Ries suggested pro-phylactic femoral nailing during TKR with simultaneous femoral plate removal to reduce the risk of fracture through the screw holes particularly in osteoporotic bone [7]. The removal of older and sometimes bulky hardware can be particularly challenging for the surgeon requiring a longer and more complex surgical procedure. Extramedullary jigs have been proposed as an alternative on the tibial side. However, femoral extramedullary instrumentation requires radiographic identification of the center of the femoral head with free hand pinning of the cutting block affecting the accuracy of implant placement [4]. The literature suggests that the outcome of TKR following femoral fractures using traditional techniques may be somewhat inferior to those seen after routine arthroplasty [1-3]. 
Computer-assisted TKR has been shown to improve implant alignment and to correct limb deformity [8-10]. Computer navigation does not require intramedullary instrumentation and can therefore be performed without femoral hardware removal. As a result, staged surgery or simultaneous hardware removal is not required avoiding the risks associated with these procedures and providing economic savings [11-13]. In Italy, the costs of hardware removal using a diagnostic related group (DRG) model are in excess of 2000 Euros.

The aim of this study was to assess the effectiveness of computerassisted TKR in managing post-traumatic arthritic joints following prior distal femoral fractures without removal of retained hardware. The study group was compared with a matched group of patients with atraumatic arthritis who underwent 'routine' TKR.

\section{Materials and methods}

In our department 789 computer-assisted primary TKR were performed between March 2001 and March 2009. In this series 23 patients were treated because of post-traumatic knee arthritis following a prior distal femoral fracture. Of these 16 patients underwent computer-assisted surgery (group I). In the remaining seven patients were excluded from the study as hardware was removed in separate procedure prior to TKR. The interval between the fracture and subsequent TKR averaged 5.8 years (range 1.912 years). Eight patients were male and eight female. In all cases the hardware used for original fracture fixation was retained. Retained hardware included a distal lateral plate and screws in seven patients, an intramedullary nail in six patients, and screws alone in three patients. In 10 patients an E.motion knee prosthesis (BBraun, Tuttlingen, Germany) was implanted using dedicated computer navigation software (Orthopilot, BBraun, Tuttlingen, Germany). In the remaining six patients a computer-assisted Genesis II TKR (Smith \& Nephew, Memphis, TN, USA) was performed using implant specific software (Vector Vision, BrainLAB, Munich, Germany).

Pre-operatively extra-articular femoral deformities were seen in four patients as a result of malunion (mean: $7.2^{\circ}$ ). The deformity was situated in the distal third of the femur in two patients and the middle third of the bone in the other two patients. In all the cases the correction of the limb deformity was planned using the prostheses and no extraarticular or intraarticular corrective osteotomy was required. In three patients implantation of the prosthesis required removal of the most distal screws in the femoral plate. This was achieved through small incisions without extension of the standardized TKR approach using a maximum 14-centimeter skin incision.

At a minimum follow-up of approximately 2 years, each patient in group I was matched with a patient who had undergone a computerassisted TKR using the same implant and software (group II). All patients in group II had atraumatic knee arthritis and had undergone knee replacement surgery in the same time period as the group I patients.

The ethics committee approved the study and prior consent to study involvement was obtained for all the patients.

Patients were matched in terms of age, gender, pre-operative range of motion, pre-operative arthritis severity according to the Albaack classification, type and grade of deformity and implant features (cruciate retaining or sacrificing). Patients were matched with a maximum difference with respect to age of 3 years, pre-operative flexion of $10^{\circ}$ and varus-valgus deformity of $5^{\circ}$ (valgus to valgus and varus to varus).

In both groups an antero-medial longitudinal knee incision and medial parapatellar arthrotomy was used. All knee implants were cemented and the same pre-operative and post-operative rehabilitation protocols were used for both groups. Passive knee flexion was delayed in the two patients who required a tibial osteotomy. Early weight bearing as tolerated was encouraged in all patients. The duration of surgery was documented in all cases. Surgery was carried out using a standard navigation technique with anatomical trackers rigidly fixed in the distal end of the femur and the proximal end of the tibia carefully avoiding the retained hardware in the distal femur in group I. Preoperatively all the knees were evaluated using the Knee Society Score [14].

At latest follow-up one author (C.C.), not involved in the original surgery, evaluated all patients using both the Knee Society Score and the WOMAC Arthritis Index (self-administered questionnaire) [15]. The surgical time, duration of hospital stay and intra-operative and post-operative complications were recorded and compared. A radiolog-ical assessment was carried out using a standardized protocol and mag-nification. Standing radiographs were obtained with the knee in maximum extension, the patella pointing forward and both hips and ankles visible on the film. The lateral radiographs were taken with the knee in $30^{\circ}$ of flexion on a radiographic film $(20 \times 40 \mathrm{~cm})$. The radiographs were repeated if malrotation was detected. These standard radiographs were used to determine the Hip-Knee-Ankle angle (HKA), frontal femoral component angle (FFC), frontal tibial component angle (FTC) and sagittal orientation (slope) of both femoral and tibial components. Two independent surgeons measured all angles on two separate occasions and the final value for each angle was derived from the mean of these measurements. The FFC was determined as the angle between the mechanical axis of the femur and the transverse axis of the femoral component. The FTC was determined as the angle between the mechanical axis of the tibia and the transverse axis of the tibial component. The slopes of the femoral and tibial component were evaluated by measuring the angle formed between a line drawn tangential to the base plate (surface in contact with bone) of the respective components and the anterior femoral cortex or mechanical tibial axis.

The ideal alignment for each parameter was determined prior to the study as a FFC angle of $90^{\circ}$, FTC angle of $90^{\circ}$, HKA angle of $180^{\circ}$, femoral slope of $90^{\circ}$ and a tibial slope of $87^{\circ}$. The total number of outliers for each parameter was determined. Outliers were defined as prostheses with any alignment parameter beyond $3^{\circ}$ of the ideal value. Statistical analysis of the results was performed through a non-parametric test (Mann-Whitney U Test) using Statistica 7.0 (StatSoft Inc., Tulsa, OK, US). A statistically significant result was given a $\mathrm{P} \leq 0.05$.

\section{Results}

The mean pre-operative ages were 69.9 years (range: 54-82) for group I and 71.3 years (range: 56-84) for group II. In each group there were eight females and eight males. The mean numbers of previous surgeries were 1.6 (range: $1-4)$ in group 1 and 0.3 (range: $0-2$ ) in group II. The mean pre-operative flexions were $105.6^{\circ}$ (range: $85-$ 125 ) and $108.7^{\circ}$ (range: $90-120$ ) for groups I and II respectively. The mean preoperative HKA angles were $175.8^{\circ}$ (range: $170-186$ ) and $174.9^{\circ}$ (range: $171-183$ ) for groups I and II respectively. There were three patients with a valgus and 13 with a varus malalignment in each group. In both groups the arthritis grade, according to Albaack, exceeded grade III in all patients. Pre-operatively the mean Knee Society Scores were 43.7 (range: $39-51$ ) in group I and 45.1 (range: 40-49) in group II. The pre-operative Functional scores were 46.9 (range: $42-52$ ) for group I and 48 (range: $42-52$ ) for group II. There were no statistically significant differences in the pre-operative data between the two groups (Table 1).

No complication specifically related to the computer navigation was seen in either group. Two patients in group I required a tibial tubercle osteotomy to obtain adequate exposure and to avoid excessive traction on the patellar tendon. In both these cases the tubercle was reattached with screws at the end of the surgery without any adverse effect on the final outcome. There were no statistically significant differences in the duration of surgical time or hospital stay (Table 2). Eleven patients in each group required postoperative blood transfusions.

At the latest follow-up (55.1 and 53.5 months respectively for groups I and II) no implant had been revised and no major signs of radiological loosening were seen in either group. The mean Knee Society Scores were 84.7 (range: 76-94) in group I and 86 (range: 76-94) in the group II. The Functional scores were 86.6 (range: 75-95) and 88.4 (range: $80-95$ ) for groups I and II respectively. No statistically significant differences were seen in the Knee Society and Function scores between the two groups (Fig. 1). The WOMAC Arthritis Index showed no statistically significant difference be-tween the two groups for pain, function and stiffness indices (Fig. 1).

The HKA angles were $179.1^{\circ}$ (range: $177-182$ ) and $178.6^{\circ}$ (range: 176-182) in group I and group II, respectively. The FFC and the FTC angles were respectively $89.6^{\circ}$ (range: $86-92$ ) and $89.6^{\circ}$ (range: $87-92$ ) in the post-traumatic group and $88.5^{\circ}$ 
Table 1

Pre-operative data for group I and group II.

\begin{tabular}{|c|c|c|c|}
\hline & $\begin{array}{l}\text { Group I } \\
\text { (Post-traumatic group) }\end{array}$ & $\begin{array}{l}\text { Group II } \\
\text { (Matched group) }\end{array}$ & P value \\
\hline Age and sex & $\begin{array}{l}69.9 \text { y (range: } 54-82 \text { ) } \\
\text { Std: } 8 \text { (eight males, } \\
\text { eight females) }\end{array}$ & $\begin{array}{l}\text { 71.3y (range: } 56-84 \text { ) } \\
\text { Std: } 7.8 \text { (eight males, } \\
\text { eight females) }\end{array}$ & 0.06 \\
\hline $\begin{array}{l}\text { Number of } \\
\text { pre-operative } \\
\text { surgeries }\end{array}$ & $\begin{array}{l}1.7 \text { (range 1-4) } \\
\text { Std: } 0.9\end{array}$ & $\begin{array}{l}0.3 \text { (range } 0-2 \text { ) } \\
\text { Std: } 0.6\end{array}$ & 0.0005 \\
\hline $\begin{array}{l}\text { Pre-operative } \\
\text { flexion } \\
\text { range }\end{array}$ & $\begin{array}{l}105.6^{\circ} \text { (range: } 85-125 \text { ) } \\
\text { Std: } 12.7\end{array}$ & $\begin{array}{l}108.8^{\circ} \text { (range: } 90-120 \text { ) } \\
\text { Std: } 9.7\end{array}$ & 0.13 \\
\hline $\begin{array}{l}\text { Pre-operative Knee } \\
\text { Society Score }\end{array}$ & $\begin{array}{l}44 \text { (range: } 39-51 \text { ) } \\
\text { Std: } 3\end{array}$ & $\begin{array}{l}45.1 \text { (range } 40-49 \text { ) } \\
\text { Std: } 2.6\end{array}$ & 0.09 \\
\hline $\begin{array}{l}\text { Pre-operative } \\
\text { Functional score }\end{array}$ & $\begin{array}{l}46.9 \text { (range: } 42-52 \text { ) } \\
\text { Std: } 3.4\end{array}$ & $\begin{array}{l}48 \text { (range: } 42-52 \text { ) } \\
\text { Std: } 2.5\end{array}$ & 0.15 \\
\hline $\begin{array}{l}\text { Pre-operative HKA } \\
\text { angle }\end{array}$ & $\begin{array}{l}175.8 \text { (range: } 170-186 \text { ) } \\
\text { Std: } 4.1\end{array}$ & $\begin{array}{l}174.9 \text { (range: } 171-183 \text { ) } \\
\text { Std: } 3.8\end{array}$ & 0.07 \\
\hline Type of deformity & $\begin{array}{l}\text { Three valgus } \\
13 \text { varus }\end{array}$ & $\begin{array}{l}\text { Three valgus } \\
13 \text { varus }\end{array}$ & \\
\hline
\end{tabular}

(range: $86-95$ ) and $88.6^{\circ}$ (range: $86-91$ ) respectively in the matched group. The slopes of the femoral component were $89.9^{\circ}$ (range: $88-94$ ) in group I and $89.6^{\circ}$ (range: $88-94$ ) in group II. The slopes of the tibial component were $87.1^{\circ}$ (range: 85-91) in group I and $87^{\circ}$ (range: 85-91) in group II. No statistically significant differences were seen for any of the radiological parameters. Only seven outliers were seen in group I and six in group II across all radiological parameters ( 80 angles in total). No statistically significant difference was seen between outliers in the two groups (Fig. 2)

\section{Discussion}

In this study we found that in appropriate patients computer-assisted TKR with retention of hardware is a very helpful tool in managing patients with post-traumatic knee arthritis following prior femoral fracture with similar results to routine TKR performed because of atraumatic arthritis.

Nevertheless in some patients undergoing TKR because of posttraumatic arthritis limb alignment restoring is difficult because fracture fixation hardware can prevent use of intra-medullary guides [1-4]. Furthermore the presence of extra-articular deformities and

Table 2

Post-operative results for group I and group II.

\begin{tabular}{|c|c|c|c|}
\hline & $\begin{array}{l}\text { Group I } \\
\text { (Post-traumatic group) }\end{array}$ & $\begin{array}{l}\text { Group II } \\
\text { (Matched group) }\end{array}$ & Pvalue \\
\hline Surgical time & $\begin{array}{l}82.6 \text { min } \\
\text { (range: 69-101) } \\
\text { Std: } 9.5\end{array}$ & $\begin{array}{l}78.5 \text { min } \\
\text { (range: } 67-105 \text { ) } \\
\text { Std: } 9.9\end{array}$ & 0.1 \\
\hline $\begin{array}{l}\text { Duration of hospital } \\
\text { stay }\end{array}$ & $\begin{array}{l}7.1 \text { (range:5-9) } \\
\text { Std: } 1.2\end{array}$ & $\begin{array}{l}7.3 \text { (range: } 6-8 \text { ) } \\
\text { Std: } 0.6\end{array}$ & 0.8 \\
\hline $\begin{array}{l}\text { Post-operative Knee } \\
\text { Society Score }\end{array}$ & $\begin{array}{l}84.7 \text { (range: } 76-94 \text { ) } \\
\text { Std: } 6.3\end{array}$ & $\begin{array}{l}86 \text { (range: } 76-94 \text { ) } \\
\text { Std: } 5.7\end{array}$ & 0.3 \\
\hline $\begin{array}{l}\text { Post-operative Functional } \\
\text { score }\end{array}$ & $\begin{array}{l}86.6 \text { (range: } 75-95 \text { ) } \\
\text { Std: } 7.4\end{array}$ & $\begin{array}{l}88.4 \text { (range: } 80-95 \text { ) } \\
\text { Std: } 5.9\end{array}$ & 0.3 \\
\hline WOMAC pain score & $\begin{array}{l}1.9 \text { (range: } 0-3 \text { ) } \\
\text { Std: } 0.9\end{array}$ & $\begin{array}{l}1.9 \text { (range: } 0-3 \text { ) } \\
\text { Std: } 0.7\end{array}$ & 0.8 \\
\hline WOMAC stiffness score & $\begin{array}{l}0.9 \text { (range: } 0-3 \text { ) } \\
\text { Std: } 0.9\end{array}$ & $\begin{array}{l}0.8 \text { (range: } 0-3 \text { ) } \\
\text { Std: } 0.7\end{array}$ & 0.8 \\
\hline WOMAC function score & $\begin{array}{l}3.9 \text { (range: } 0-6 \text { ) } \\
\text { Std: } 1.8\end{array}$ & $\begin{array}{l}4 \text { (range: } 2-6 \text { ) } \\
\text { Std: } 1.4\end{array}$ & 0.8 \\
\hline $\begin{array}{l}\text { Post-operative } \\
\text { HKA angle: }\end{array}$ & $\begin{array}{l}179.1^{\circ} \\
\left(\text { range: } 177^{\circ}-182^{\circ}\right) \\
\text { Std: } 1.7\end{array}$ & $\begin{array}{l}178.6^{\circ} \\
\text { (range: 176-182) } \\
\text { Std: } 1.5\end{array}$ & 0.2 \\
\hline $\begin{array}{l}\text { Post-operative } \\
\text { FFC angle }\end{array}$ & $\begin{array}{l}89.6^{\circ} \text { (range: } 86-92 \text { ) } \\
\text { Std: } 1.6\end{array}$ & $\begin{array}{l}88.5^{\circ} \text { (range: } 86-95 \text { ) } \\
\text { Std: } 1.5\end{array}$ & 0.08 \\
\hline $\begin{array}{l}\text { Post-operative } \\
\text { FTC angle }\end{array}$ & $\begin{array}{l}89.6^{\circ} \text { (range: } 87-92 \text { ) } \\
\text { Std: } 1.6\end{array}$ & $\begin{array}{l}88.6^{\circ} \text { (range: } 86-91 \text { ) } \\
\text { Std: } 1.2\end{array}$ & 0.08 \\
\hline $\begin{array}{l}\text { Post-operative femoral } \\
\text { slope }\end{array}$ & $\begin{array}{l}89.9^{\circ} \text { (range: } 88-94 \text { ) } \\
\text { Std: } 1.5\end{array}$ & $\begin{array}{l}89.6^{\circ} \text { (range: } 88-94 \text { ) } \\
\text { Std: } 1.5\end{array}$ & 0.6 \\
\hline $\begin{array}{l}\text { Post-operative tibial } \\
\text { slope }\end{array}$ & $\begin{array}{l}87.1^{\circ} \text { (range: } 85-91 \text { ) } \\
\text { Std: } 1.9\end{array}$ & $\begin{array}{l}87^{\circ} \text { (range: } 85-91 \text { ) } \\
\text { Std: } 1.4\end{array}$ & 0.9 \\
\hline Number of outliers & 7 & 6 & 1.0 \\
\hline
\end{tabular}

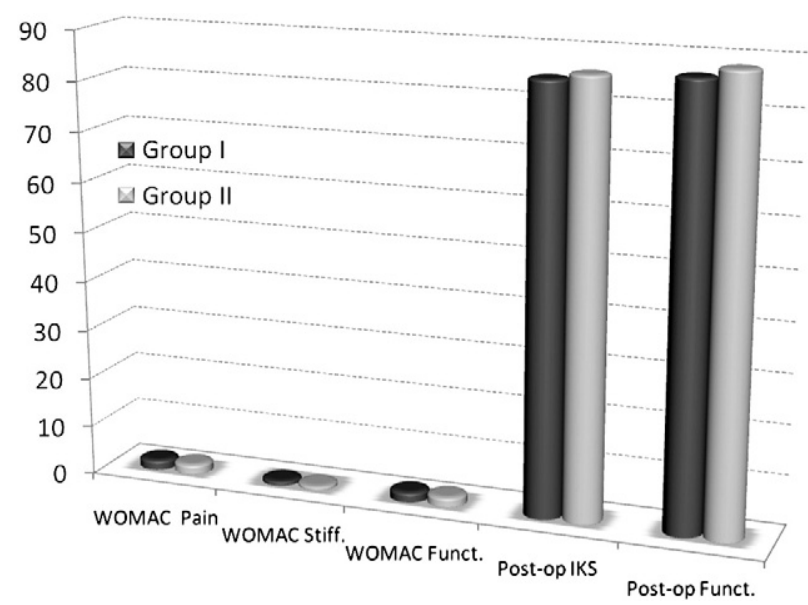

Fig. 1. Comparison of the results of group I and group II for the WOMAC arthritis indices and Knee Society Scores.

intra-medullary sclerosis can further jeopardize accurate prosthesis implantation using traditional alignment systems [11-13,16-20] (Fig. 3).

Hardware removal at the time of prosthesis implantation results in stress risers at the site of each screw hole and therefore may lead to concern about potential peri-prosthetic fracture $[5,6]$. This can result in the need to use more complex TKR implants. In older patients with osteoporotic bone these concerns can lead to a slower post-operative rehabilitation program. In particular, restrictions on weight-bearing and continuous passive motion in these patients may delay recovery [1-3]. An alternative solution in these cases has been staged surgery. These techniques involve initial hardware re-moval, on occasion combined with prophylactic femoral nailing, followed by delayed TKR. However, the benefits of these two stage procedures must be weighed up against the increased risk of complications such as infections and arthrofibrosis [1,2]. Unfortunately, the results of TKR combined with either hardware removal performed at the time of prosthesis implantation or in a delayed fashion have been reported as "inferior" to routine TKR [1-3] (Fig. 4).

Computer-assisted TKR using a surgical navigation system has been shown in the literature to offer at least similar results in terms of accu-racy to traditional alignment guides [8-10]. It enables the surgeon to make accurate bone cuts, orient the implants correctly and provide a good qualitative intraoperative assessment of ligament balance and kinematics. In addition, the intra-medullary canal is left intact when a computer navigation technique is used [8-10]. The ability to implant a TKR accurately without the use of femoral intra-medullary guides is particularly useful in patients with posttraumatic arthritis following a prior femoral fracture and retained hardware [11]. Despite the potential advantages of computerassisted TKR in patients with prior femoral fracture and retained hardware, there are only two studies in the

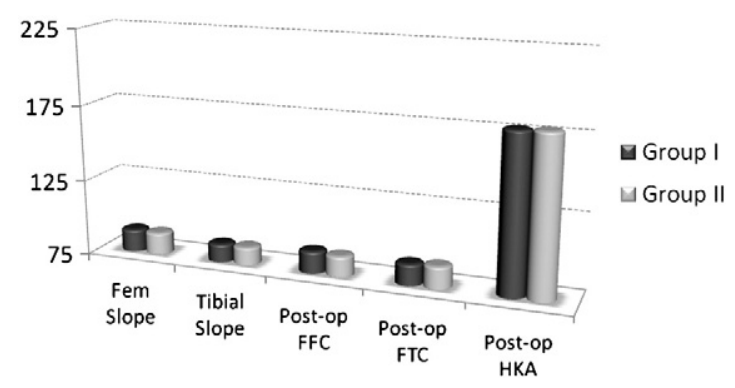

Fig. 2. Postoperative alignment as measured on standardized radiographs for groups I and II (FFC: frontal femoral component angle; FTC: frontal tibial component angle; HKA: mechanical axes). 


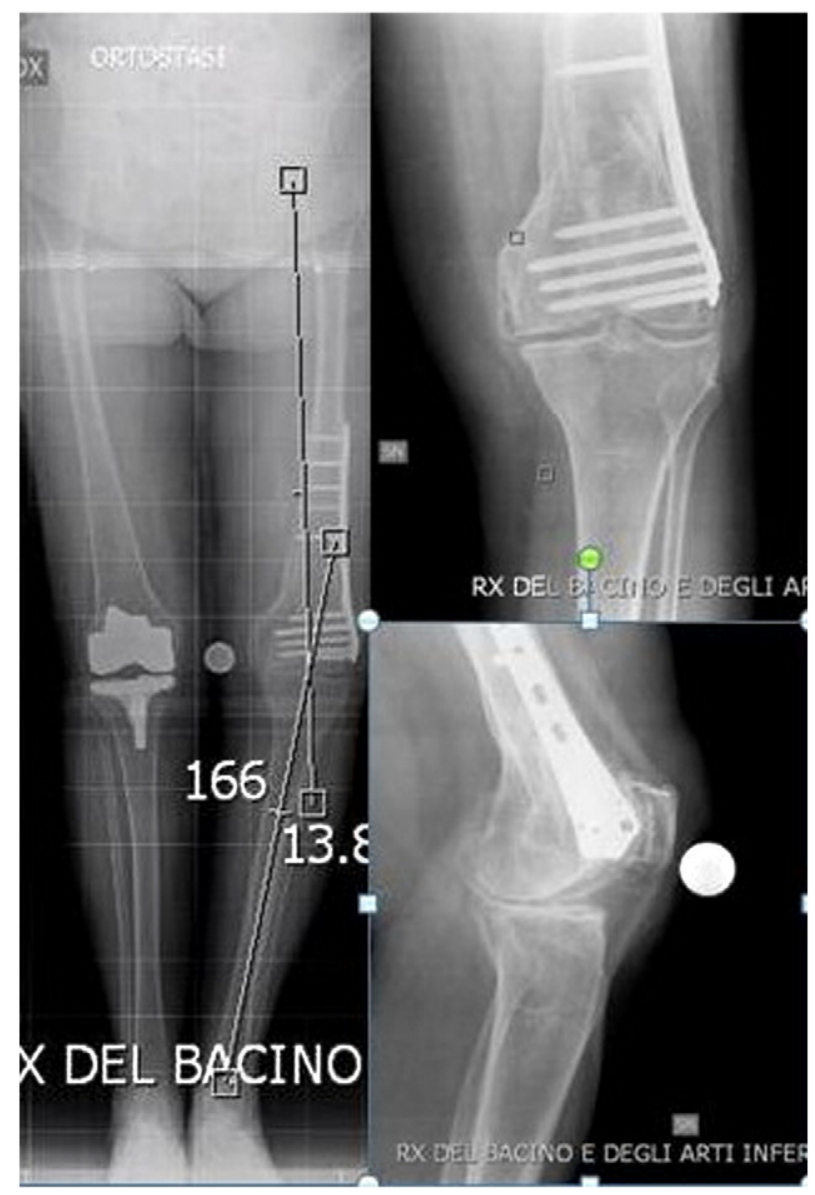

Fig. 3. Pre operative long standing radiographs of a post traumatic knee following a supracondylar fracture with a residual varus deformity.

literature reporting two and five cases respectively [12,13]. In both these studies computer navigation was used to facilitate TKR while retaining fracture fixation hardware in patients with prior femoral frac-tures and well aligned femurs. Kim et al. reported two cases treated successfully using a navigated TKR with modified self-tapping femoral anchoring pins [12]. Tigani et al. documented five cases successfully managed using traditional bicortical pins [13] (Fig. 5).

In this study a series of navigated TKRs with retention of fracture fixation hardware following prior femoral was matched with a similar primary navigated TKR performed because of atraumatic arthritis and to our knowledge this study is the largest published in literature. Patients were matched for age, gender, pre-operative range of motion, preoperative arthritis severity according to the Albaack classification, type and grade of deformity. In addition, patients were also matched for type of implant and computer navigation software used. All the TKR were performed with standard navigation tools with bicortical tools and a routine approach using a maximum 14-centimeter skin incision. For patients in the post-traumatic group contact with the retained hard-ware was avoided by insertion of the femoral pins directly through the surgical incision rather than the routine percutaneous insertion. At the final assessment there were no significant differences between the two groups in terms of surgical time, duration of hospital stay, clinical results and radiological outcomes. All the posttraumatic patients were managed successfully with a one-stage procedure retaining the hardware. In three cases the fracture fixation plate was retained and the most distal screws removed to avoid the possibility of impingement on the femoral shield. No computer navigation specific complications were seen in either group despite the use of two different types of implant and software.

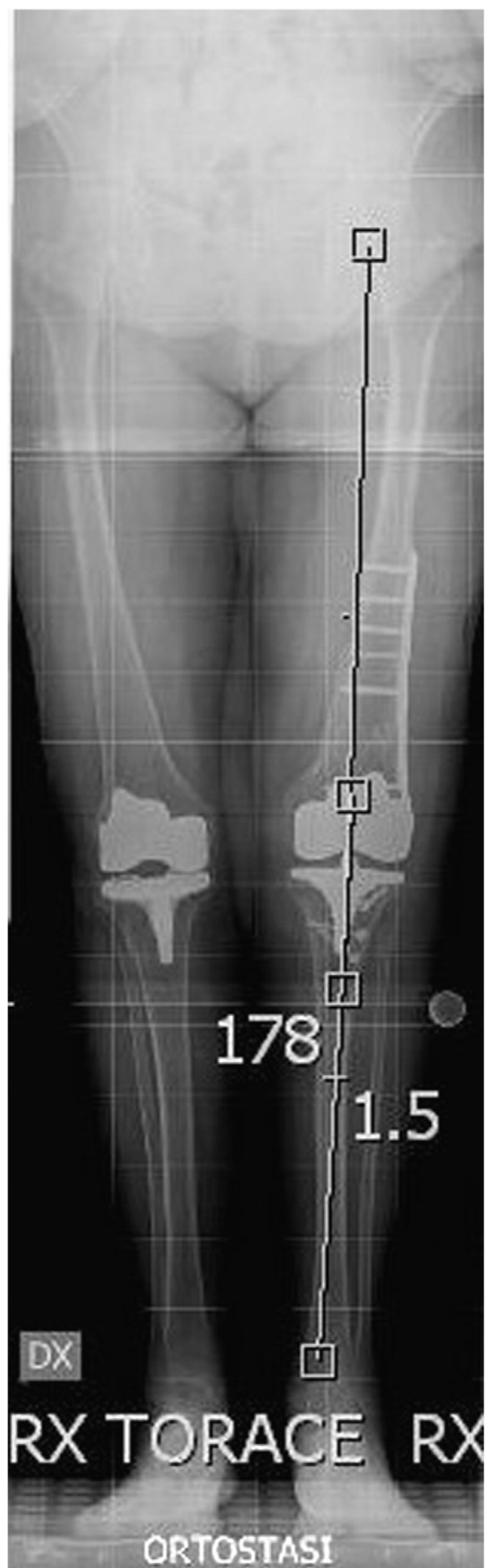

Fig. 4. Post operative long standing radiographs with a well aligned limb maintaining the hardware.

Retention of fracture fixation hardware did not cause any difficulties with either the navigation or implantation processes.

The weaknesses of this study include the use of different implants and software, the variation in surgical technique in two patients in 


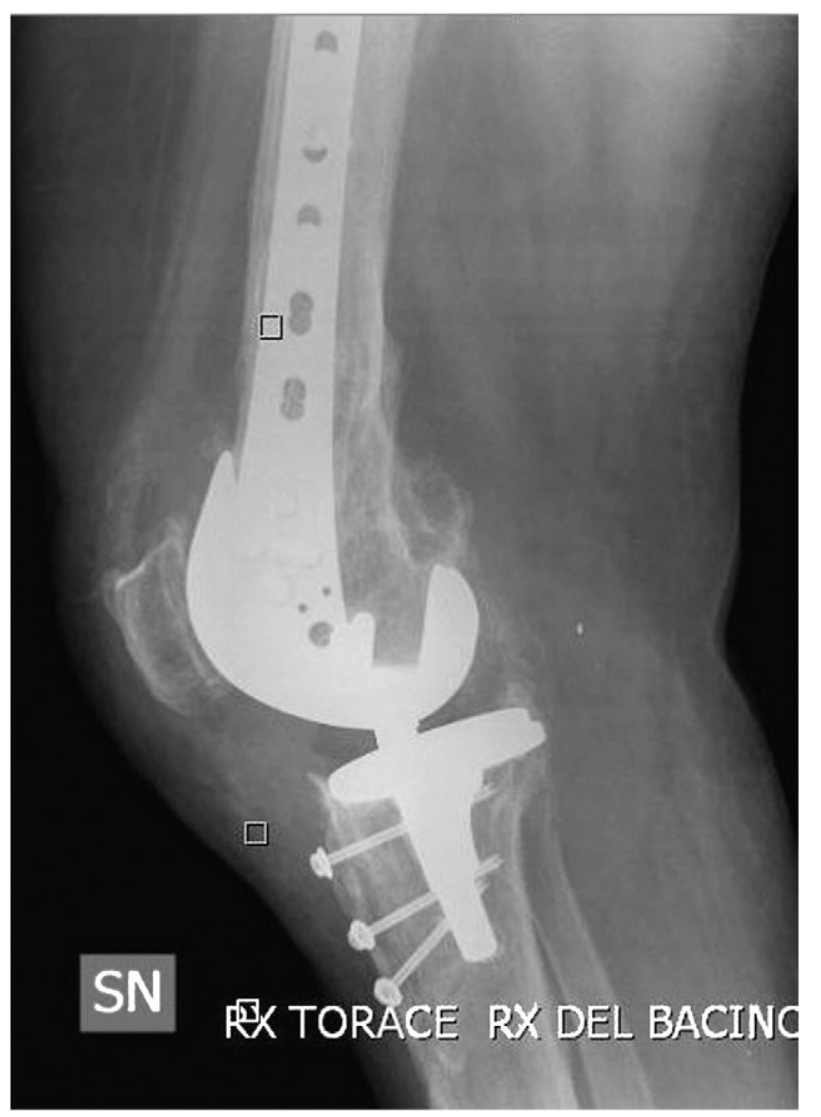

Fig. 5. Post operative lateral radiographs of the knee showing a complete healing of the osteotomized anterior tibial tubercle.

the post-traumatic group (tibial tuberosity osteotomy) and the involvement of different operating surgeons. In addition, the study would have been improved if the data had been collected prospectively and a radiological assessment had been undertaken using a 3D evaluation of alignment with a CT based protocol as described in literature [21].

In conclusion we believe based on own experience, that computer navigation allows the surgeon to obtain good reproducible results similar to a routine TKR with a one-stage TKR without hardware removal in post traumatic knee arthritis following prior femoral fracture.

However we do not advocate retention of femoral hardware in all cases. In patients requiring quadriceps release or with symptomatic hardware a two-stage procedure is advisable. In younger patients in particular, hardware removal is recommended prior to TKR even if it is asymptomatic because of the likelihood of future revision surgery perhaps requiring stemmed implants.

\section{Conflict of interest}

The authors declare that they have no conflict of interest.

\section{References}

[1] Papadopoulos EC, Parvizi J, Lai CH, Lewallen DG. Total knee arthroplasty following prior distal femoral fracture. Knee 2002;9(4):267-74

[2] Weiss NG, Parvizi J, Hanssen AD, Trousdale RT, Lewallen DG. Total knee arthroplasty in post-traumatic arthrosis of the knee. J Arthroplasty 2003;18(3Suppl 1):23-6.

[3] Wu LD, Xiong Y, Yan SG, Yang QS. Total knee replacement for posttraumatic degenerative arthritis of the knee. Chin J Traumatol 2005;8(4):195-9.

[4] Baldini A, Paolo Adravanti P. Less invasive TKA: extramedullary femoral reference without navigation. Clin Orthop Relat Res 2008;466(11):2694-700.

[5] Brooks DB, Burstein AH, Frankel VH. The biomechanics of torsional fractures. The stress concentration effect of a drill hole. J Bone Joint Surg Am 1970;52(3): 507-14.

[6] Johnson BA. Fallat LM The effect of screw holes on bone strength. J Foot Ankle Surg 1997;36(6):446-51

[7] Ries MD. Prophylactic intramedullary femoral rodding during total knee arthroplasty with simultaneous femoral plate removal. J Arthroplasty 1998;13(6):718-21.

[8] Confalonieri N, Manzotti A, Pullen C, Rangone V. Computer-assisted technique versus intramedullary and extramedullary alignment systems in total knee replacement: a radiological comparison. Acta Orthop Belg 2005;71(6):703-97.

[9] Cheng T, Pan XY, Mao X, Zhang GY, Zhang XL. Little clinical advantage of computer-assisted navigation over conventional instrumentation in primary total knee arthroplasty at early follow-up. Knee 2012 Aug;19(4):237-45.

[10] Pang $\mathrm{CH}$, Chan WL, Yen $\mathrm{CH}$, et al. Comparison of total knee arthroplasty using computer-assisted navigation versus conventional guiding system: a prospective study. J Orthop Surg (Hong Kong) 2009;17(2):170-3.

[11] Martin A, Wohlgenannt O, Prenn M, von Strempel A. Post-traumatic osteoarthritis of the knee: special indication for navigation TKA. Unfallchirurg 2008;111(9):754-8.

[12] Kim KK, Heo YM, Won YY, Lee WS. Navigation-assisted total knee arthroplasty for the knee retaining femoral intramedullary nail, and distal femoral plate and screws. Clin Orthop Surg 2011;3(1):77-80

[13] Tigani D, Masetti G, Sabbioni G, Ben Ayad R, Filanti M, Fosco M. Computer-assisted surgery as indication of choice: total knee arthroplasty in case of retained hardware or extra-articular deformity. Int Orthop 2012;36(7):1379-89.

[14] Insall JN, Dorr LD, Scott RD, Scott WN. Rationale of the Knee Society clinical rating system. Clin Orthop 1998;248:13-4.

[15] Bellamy N, Buchanan WW, Goldsmith CH, Campbell J, Stitt LW. Validation study of WOMAC: a health status instrument for measuring clinically important patient relevant outcomes to antirheumatic drug therapy in patients with osteoarthritis of the hip and knee. J Rheumatol 1988;15:1833-40.

[16] Kuo CC, Bosque J, Meehan JP, Jamali AA. Computer-assisted navigation of total knee arthroplasty for osteoarthritis in a patient with severe posttraumatic femoral deformity. J Arthroplasty 2011;26(6):976.e17-20.

[17] Bottros J, Klika AK, Lee HH, Polousky J, Barsoum WK. The use of navigation in tota knee arthroplasty for patients with extra-articular deformity. J Arthroplasty 2008;23(1):74-8.

[18] Mullaji A, Shetty GM. Computer-assisted total knee arthroplasty for arthritis with extra-articular deformity. J Arthroplasty 2009;24(8):1164-9.

[19] Klein GR, Austin MS, Smith EB, Hozack WJ. Total knee arthroplasty using computer-assisted navigation in patients with deformities of the femur and tibia. J Arthroplasty 2006;21(2):284-8.

[20] Patai J, Janositz G, Mécs L, Tóth K. Navigated total knee arthroplasty in a patient with severe diaphyseal deformities. Acta Orthop Belg 2007;73(4):536-40.

[21] Chauhan SK, Clark GW, Lloyd S, Scott RG, Breidahl W, Sikorski JM. Computer-assisted total knee replacement. A controlled cadaver study using a multi-parameter quantitative CT assessment of alignment (the Perth CT Protocol). J Bone Joint Surg Br 2004;86(6):818-23. 